\title{
Difficult Extraction of Post-Endodontically Treated Upper Second molar : A Case Report
}

\author{
Zubair Ahmed and Ashvini Kishor Vadane* \\ Oral and Maxillofacial Surgery, MA Rangoonwala dental college, India
}

Received: October 26, 2017; Published: November 01, 2017

*Corresponding author: Ashvini Kishor Vadane, Oral and Maxillofacial Surgery MA Rangoonwala dental college, Pune, India, Email: drashvinivadane@gmail.com

\section{Abstract}

The ideal tooth extraction is "the painless removal of the whole tooths, or roots, with minimal trauma to the investing tissues, so that the wound heals uneventfully \& no post-operative prosthetic problem is created. The present article reports a case of difficult extraction in 39 years female. The aim of the article is to report a case of difficult extraction of post-endodontic ally treated upper second molar.

\section{Case Report}

A 39 years female patient was complaining of pain in the upper left back teeth region of jaw since 8 days. The patient was under root canal treatment with upper left second molar (Figures 1,2) and was complaining of pain with the same tooth [1]. On radiographic examination, it revealed that there is extended endodontic file in the molar's mesial canal, which was extended beyond the root. This tooth had poor prognosis as well as patient was not ready to continue the root canal treatment due to pain, hence we decided to perform extraction of it. This extraction was challenging as there were more chances of breakage of endodontic file but we did it successfully. Maxillary cow-horn forceps was used for extraction. Tooth was extracted with minimal trauma and without breakage of endodontic file [2-6].

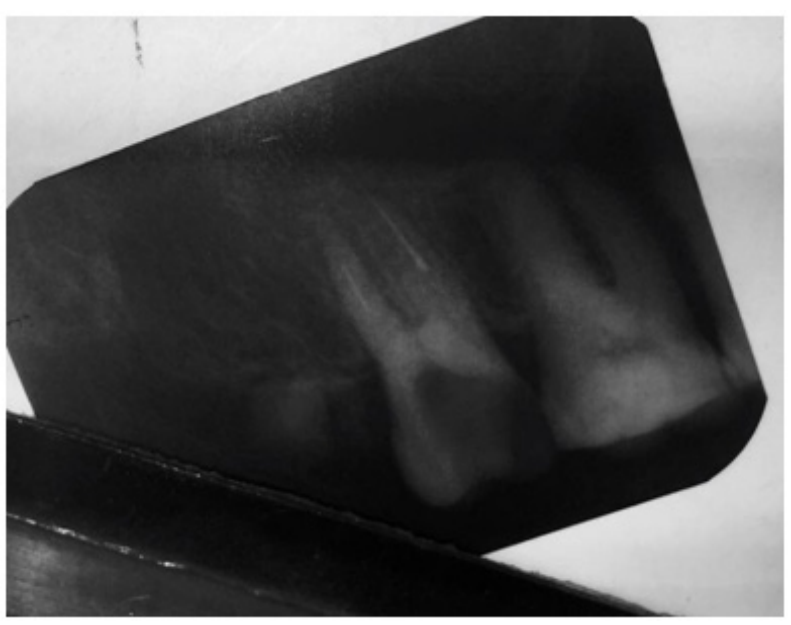

Figure 1: IOPA of left upper second molar.

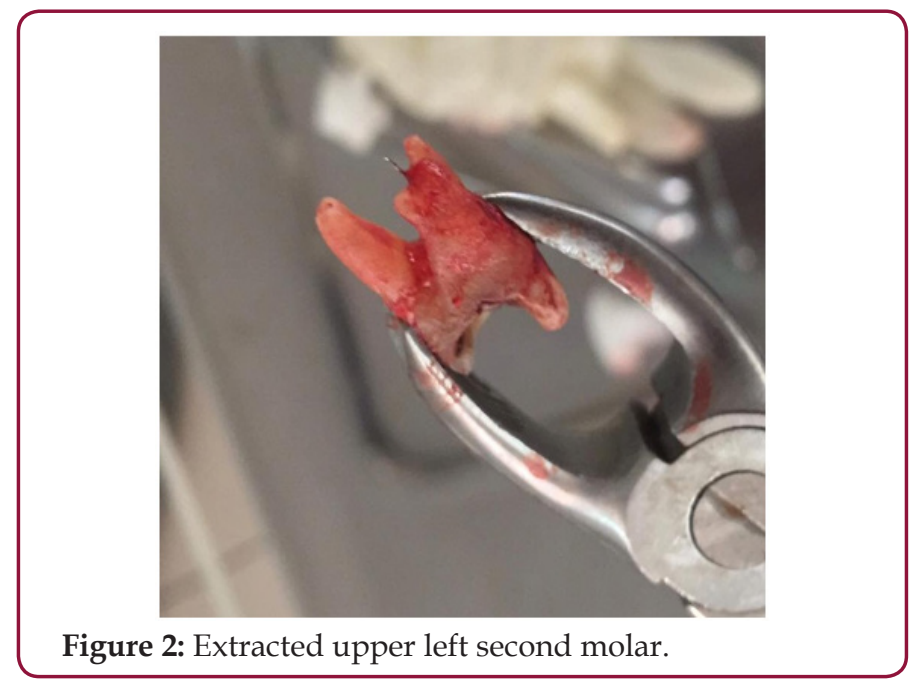

\section{Discussion}

The ideal tooth extraction is "the painless removal of the whole tooths, or roots, with minimal trauma to the investing tissues, so that the wound heals uneventfully \& no post-operative prosthetic problem is created.

Tooth extraction should be considered as a last option. Permanent teeth are extracted for various reasons such as dental caries, orthodontic reasons, periodontal disease, impacted teeth, failed dental treatments, pre-prosthetic considerations etc. [7]. Criterias which are taken into consideration before any extraction are tooth mobility, prosthetic planning, severity of attachment loss, furcation involvement, endodontic-periodontal lesion, radiographic bone loss ( more than $50 \%$ ) , grossly carious teeth [8]. 
Endodontic ally treated teeth are prone to extraction mainly due to non- restorable caries, endodontic failure, iatrogenic perforation, vertical root fractures [9]. Any endodontic treatment is been evaluated at several levels which starts at the success of treatment in preventing periapical lesions [10]. The complications which come across while performing extraction are tooth fracture, fracture of cortical plates, alveolar osteitis, trismus, postoperative pain, haemorrhage, wound dehiscence. Rare complications are luxation of adjacent teeth, maxillary tuberosity fracture, and displacement of tooth into adjacent tissue spaces [11]. Fcortical plates are fractured while doing extraction, it can lead to ridge narrowing and this may interfere with closure of extraction space [12]. The case mentioned in the article is a difficult case of extraction. But we performed it successfully and with fewer traumas to surrounding tissue.

\section{References}

1. William Ersner (1924) Some accidents and complications in exodontias. American Journal of Orthodontics and Dentofacial Orthopedics 10(10): 651-653.

2. Gokul Parameswar Venkateshwar, Mukul Nandkumar Padhye, Aman Rajiv Khosla, Shruti Tejprakash Kakkar (2011) Complications of exodontia: A retrospective study. Indian Journal of Dental Research 22(5): 633-638.

3. Y Nakagawa, F Kanaya, A Tsuno,Y Maruoka, Y Kikuchi, S Oka (2011) Exodontia related complications at a Japanese hospital with a major HIV / AIDS treatment center 40(10): 1148.

4. Carl D Lucas (1917) Exodontia. The Journal of The American Dental Association 4(10): 1156-1160.
5. AK Dantas, A Shinagawa, MZ Deboni (2010) Assessment of Preclinical Learning on Oral Surgery Using Three Instructional Strategies. Journal of Dental Education 74(11): 1230-1236

6. Frank W Rounds (1951) Principles and technique of exodontia . Oral Surgery Oral Medicine Oral Pathology 37(1): 18-24.

7. M Jafarian, A Etebarian (2013) Reasons for Extraction of Permanent Teeth in General Dental Practices in Tehran. Iran Med Princ Pract 2013 22(3): 239-244.

8. Carlos Heitor Cunha Moreira, Fabricio Batistin Zanatta ,Raquel Antoniazzi ,Priscila Ceolin MENEGUETTI , Cassiano Kuchenbecker Rosing (2007) Criteria adopted by dentists to indicate the extraction of periodontally involved teeth. Journal of Applied Oral Science 15(5): 431-441.

9. Yehuda Zadik, Vadim Sandler, Ran Bechor, Robert Salehrabio (2008) Analysis of factors related to extraction of endodontically treated teeth. Oral Surg Oral Med Oral Pathol Oral Radiol Endod 106(5): e31- e35.

10. Jovito Adiel Skupien, Niek J Opdam, Rolf Winnen, Ewald M Bronkhorst, Cees M Kreulen, et al. (2016) Survival of Restored Endodontically Treated Teeth in Relation to Periodontal Status. Brazilian Dental Journal 27(1): 37-40.

11. Jay W Friedman (2007) The prophylactic Extraction of Third Molars: A Public Health Hazard. American Journal of Public Health 97(9): 15541559.

12. Ambesh Kumar Rai, Bipin Kumar Yadav (2011) Facilitating Orthodontic teeth extraction -A technique suggestion . The Saudi Journal for Dental Research 7(2): 96-100.

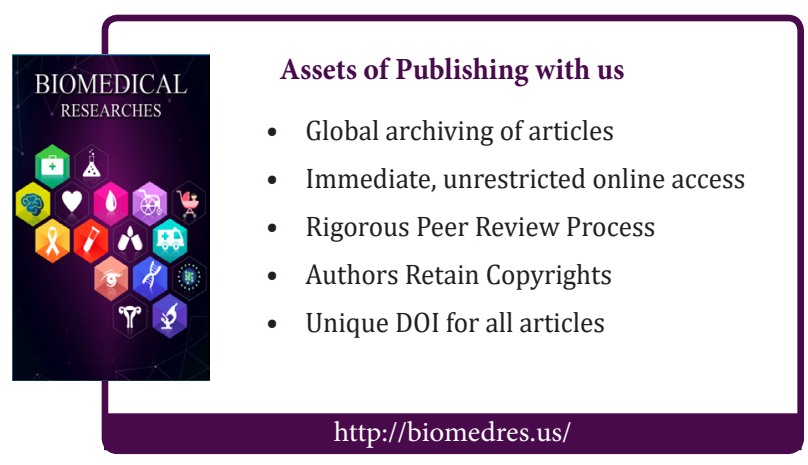

